\title{
POLIITICA E LITERATURA NA GOA OITOCENTISTA: EM TORNO DA CONSTRUÇÃO DE UM UNIVERSO DE ESCRITORES PERISTAS'
}

\section{POLITICS AND LITERATURE IN NINETEENTH CENTURY GOA: NOTES ON THE CONSTRUCTION OF A UNIVERSE OF PERISTA URITERS}

\author{
Luís P. L. Cabral de Oliveira²
}

RESUMO: $O$ presente trabalho pretende realçar a originalidade e importância do contributo goês para a política ultramarina portuguesa do século XIX enfatizando o papel de Bernardo Peres da Silva e do perismo (uma forma de organização constitucional criada na sequência da introdução do liberalismo no Estado da Índia), bem como de uma série de autores pertencentes às elites naturais católicas cujos escritos mantiveram e robusteceram o legado de Peres.

PALAVRAS-CHAVE: Goa, Bernardo Peres da Silva, perismo, elites naturais católicas.

ABSTRACT: This work aims to underline Goa's original and important contribution to Portugal's overseas policy in the nineteenth century by emphasizing the part played by Bernardo Peres da Silva and perismo, a form of Constitutional interpretation created after the introduction of liberalism in the Estado da Índia as well as the contribution of some Goan authors for the conservation and enhancement of perismo.

KEYWORDS: Goa, Bernardo Peres da Silva, perismo, Native Catholic Elites.

1 Este texto foi desenvolvido no âmbito do Projeto Temático Pensando Goa, financiado pela FAPESP (Proc.2014/15657-8).

2 Pesquisador do Centro de Investigação e Desenvolvimento sobre Direito e Sociedade da Faculdade de Direito da Universidade Nova de Lisboa e professor do Escola Superior de Tecnologia e Gestão - Politécnico de Leiria. 
Em janeiro de 1835, Goa foi assolada por uma grande comoção: em substituição de D. Manuel de Portugal e com o título de prefeito, chegava o novo responsável político pelo Estado. Tratava-se de um membro destacado das elites naturais católicas: ${ }^{3}$ Bernardo Peres da Silva. O "conspicuo patriota" firmava o seu lugar na história do Estado da Índia e de Portugal. Para os admiradores das gerações que se lhe seguiram, tornara-se digno de figurar

in capite anguli, não só pela sua illustração, admiravel coragem, caracter independente, decidida adhesão á causa da sr.a D. Maria 2.a pela qual expoz á eminente risco a sua vida, mas porque por estes e outros titulos mereceu do immortal D. Pedro 4.0 a ventura de ser elevado á grandeza da 1.a auctoridade do seu paiz natal, com o titulo de = prefeito do Estado da India portug[u]esa (ABREU, 1874, p. 34).

Como terá Peres aqui chegado? De que forma um participante ativo na deposição do regime absolutista - apesar de não ter sido contemplado com um assento em qualquer das juntas provisionais (o que, a médio prazo, poderá ter funcionado a seu favor: se por um lado estivera do lado dos liberais desde o primeiro momento, por outro não vira a sua imagem e ação prejudicadas pelas

3 Falo do grupo composto pelas mais influentes famílias de origem goesa, provenientes das Velhas Conquistas (Bardez, Salsete e Ilhas de Tisswary), que aderiram ao catolicismo e se vieram a ocidentalizar gradualmente através de um processo que lhes permitiu conservar alguns traços importantes de épocas anteriores. Estas famílias, que prezavam não ter mistura de sangue europeu apesar de terem adotado fórmulas, modelos e padrões ocidentalizados em inúmeros domínios, foram as principais responsáveis pela conservação e funcionamento da máquina judicial, burocrática e religiosa do Estado pelo menos desde o século XVIII, assumiram um papel preponderante nas dinâmicas políticas locais a partir do liberalismo constitucional e souberam articular, por vezes com rara habilidade e grande originalidade, privilégios herdados de regimes anteriores (como o sistema gancarial e o regime do mundcarato), com apanágios da nobreza política e civil portuguesa. No universo das elites católicas goesas coexistiam, de forma muitas vezes tensa, quer com os reinóis (isto é, europeus vindos de Portugal, nomeados para o desempenho de uma comissão ou preenchimento de um lugar na administração civil, judicial ou religiosa na Índia) quer com os descendentes (de europeus; ou seja, todos aqueles que tinham nascido em Goa ou noutros territórios do Estado da Índia e que, pelo menos em teoria, eram filhos ou netos exclusivamente de portugueses, sem qualquer vestígio de ascendência indiana). Para maiores desenvolvimentos sobre o tema, XAVIER, 1846, p. 76 e segs.; LOPES e MATOS, 2006, p. 15-71; LOPES, 1999, p. 98-112; THOMAZ, 1998, p. 245-289; OLIVEIRA e COSTA, 2010, p. 55-112; OLIVEIRA, 2016 a. 
dificuldades que mancharam aqueles primeiros governos) $)^{4}$ - logrou obter semeIhante reconhecimento por parte de um monarca que pouco conhecia do Estado da Índia? A instauração do regime parlamentar e dos círculos ultramarinos desempenhou um papel fundamental neste processo.

Peres foi deputado às Cortes, por Goa, antes e depois da sua passagem pela prefeitura. No entanto, apenas participou efetivamente nelas a partir da sua terceira eleição. Quais são as razões que justificam esta particular carreira parlamentar?

A primeira eleição de Peres para representante do Estado da Índia nas Cortes teve lugar a 14 de janeiro de 1822 . Governava pois a segunda junta provisional ${ }^{5}$. $\mathrm{O}$ dia foi repleto de emoções fortes e terminou com um resultado para muitos inesperado: os candidatos mais votados foram dois naturais católicos (Peres e Constâncio Roque da Costa, ambos brâmanes) ${ }^{6}$ e o reinol Lima Leitão, homem bem conhecido pela "amizade estreita com que tratava com Bernardo Peres da Silva e outros caudilhos do povo, e esta circumstancia bastava para que o diploma de deputado the fosse offerecido" (MIRANDA, 1865, p. 89). Barreto Miranda justifica a escolha de Lima Leitão de duas formas: por um lado, tratar-se-ia de

4 Para uma análise mais detalhada deste período, aconselha-se a leitura de ABREU, 1862; BRUTO DA COSTA, 1920, p. 2-13 e 75-94; PEREIRA e MENEZES, 1835; MIRANDA, 1864a, p. 129 (sustentando uma perspetiva perista) e AYALLA, 2011 (com uma visão bem menos favorável à ação do prefeito e dos seus seguidores). Estas diferenças repercutem-se nos jornais da época, muito politizados, de entre os quais destaco o já referido "Echo da Lusitania" e "O Investigador Portuguez em Bombaim". No que toca aos periódicos políticos, MIRANDA, 1864b, p. 103-104; e OLIVEIRA, 2014, p. 196-200.

5 A primeira junta manteve-se em funções apenas entre 17 de setembro e 3 de dezembro de 1821. Considera-se que gozou do favor geral dos povos da Índia durante muito pouco tempo e que depressa se começou a conspirar no sentido de apressar a sua queda. O processo foi acelerado com a chegada de um novo governador-geral enviado por Lisboa antes da proclamação da Constituição no reino: D. Manuel da Câmara. Este, ao perceber que não tinha hipóteses de assumir o poder enquanto a junta se mantivesse em funções, acabou por se associar ao partido dos descontentes e participar ativamente na deposição do governo em exercício. Foi o que aconteceu na madrugada do dia 3 de dezembro, altura em que ascende aquela que ficou conhecida por segunda junta provisional (confirmada a 8 de dezembro). Os seus membros juraram a Constituição e resistiu até 18 de outubro de 1822.

6 Constâncio Roque da Costa morreu no exílio, em Damão, a 31 de dezembro de 1835. Para uma visão muito favorável da sua vida e obra veja-se COSTA, 1873, p. 19-33. Está por estudar o legado deste advogado goês na criação da corrente que veio a ser designada por perismo - sendo naturalmente impossível determinar qual o papel que teria jogado no seu desenvolvimento caso não tivesse desaparecido precocemente. 
uma estratégia destinada a demonstrar que o perismo não era património e interesse exclusivo das elites naturais católicas; por outro, jogaram os interesses próprios do eleito (MIRANDA, 1865, p. 89-90). A consternação instalou-se imediatamente perante o que foi, para todos os efeitos, uma entrada de leão do perismo. Note-se, no entanto, que uma leitura fria das circunstâncias apontava nesse sentido. Quem percorra os minuciosos relatos de Barreto Miranda e conheça a sociedade goesa da época rapidamente conclui que o grosso dos eleitores provinciais provinham, na sua esmagadora maioria, das elites naturais católicas (MIRANDA, 1865, p. 83-85). ${ }^{7}$ Assim, a seleção destes, ainda antes da eleição de Peres pode, portanto, ser tida como a primeira vitória visível do perismo. Doravante, jamais o cenário político goês poderia ser igual. Passaria a estar irremediavelmente dividido em duas grandes fações ou partidos que depressa se começaram a guerrear intensamente. De um lado, os peristas, entre os quais se encontrava a maioria das elites naturais católicas, alguns membros das elites descendentes e uma mão-cheia de reinóis. Protestavam ser radicalmente liberal-constitucionais e começavam a dar mostras de ter um plano político para introdução de alterações profundas em Goa. De outro, os anti-peristas, geralmente considerados mais conservadores, por agregarem quer os alegados defensores de um constitucionalismo moderado quer os adeptos do antigo regime que encaravam com profunda apreensão as propostas do grupo rival.

No entanto,

Não tendo da 1.a vez podido entrar nas côrtes porque tinham sido dissolvidas e derribada a constituição em 1823, foi o sr. Peres um dos poucos deputados que protestaram contra estes actos, e voltou á Goa nomeado intendente da agricultura, cargo que o governo local lhe não deixou exercer, porque o da metrópole se não descuidára de recomendar a maxima vigilancia na conducta politica deste funccionario (ABREU, 1874, p. 35; no mesmo sentido, COSTA, 1997, vol. III, p. 53).

Ora, durante o período em que os deputados se deslocavam a Lisboa e tornavam a Goa, o Estado vivia momentos politicamente muito complicados. A escolha do substituto de Lima Leitão na junta provisional gerara um enorme

7 As genealogias das famílias que constituíam as elites naturais das quais provêm boa parte dos eleitores foi feita em OLIVEIRA, 2014, anexo IV. 
mal-estar entre peristas e anti-peristas e redundou na chamada bardezada ou inconfidência de Bardez de maio de 1822, duramente reprimida pelos governantes. Este estado de absoluta instabilidade foi aproveitado pelo exército da Índia, que depressa tomou de facto as rédeas do poder: exigiu a expulsão dos territórios do Estado de muitos dos mais destacados defensores do liberalismo constitucional em Goa e foi gradualmente condicionando a governação da junta enquanto impedia que a mesma apresentasse demissão. Também nesta altura os prelos modernos recém-instalados em Goa desempenharam um papel determinante. O lugar de Lima Leitão na imprensa do Estado e na redação da Gazeta de Goa fora ocupado pelo velho liberal de origem brasileira, Luís Prates, então oficial-mor da secretaria-geral e adepto de Peres. Prates não estava, naturalmente, satisfeito com o volte-face resultante da intervenção do exército. Assim, aproveitou a sua posição não só para atrasar as publicações ordenadas pelo exército como para fazer imprimir e circular folhetos anónimos que lhe eram manifestamente adversos. Virá a ser assassinado a 15 de junho de 1822, rapidamente se tornando num dos mártires da causa liberal-constitucional goesa e dos peristas em particular.

Peres da Silva apresentou-se novamente como candidato nas segundas eleições para a escolha dos deputados a enviar para Lisboa, já no governo de D. Manuel de Portugal e Castro. O escrutínio teve lugar a 18 de novembro de 1827. D. Manuel rapidamente se tornou num dos principais rivais de Peres e, consequentemente, num dos dois líderes do partido anti-perista. $O$ outro era Manuel Felicíssimo Lousada de Araújo e Azevedo, nomeado desembargador da Relação de Goa, tendo chegado na mesma altura do futuro governador (OLIVEIRA, 2014, p. 17-107). O primeiro grande foco de desentendimento foi precisamente a eleição de 1827. Uma vez mais, depois de processo renhido contra o candidato abertamente apoiado pelo governador, Bernardo Peres é eleito. O clima em Goa torna-se ainda mais tenso, enquanto Peres torna a partir para Lisboa. $E$, ironicamente, uma vez aí chegado volta a encontrar as cortes encerradas por restauração do absolutismo. Peres, não querendo retornar a Goa - onde certamente se esgotaria a enfrentar a rivalidade declarada de D. Manuel de Portugal -, opta, à semelhança de tantos correligionários seus, por partir para o exílio em Inglaterra, mais concretamente em Plymouth, onde não só aprofundou os seus conhecimentos em ciência política como também estabeleceu uma rede de contactos que lhe virá a ser proveitosa (ABREU, 1874, p. 35-36). 
De lá rumou, sempre exilado, para o Brasil. Está por fazer a história das passagens do futuro prefeito do Estado da Índia pelo continente - quer na sequência da sua primeira eleição, a caminho de Lisboa, quer nos anos de exílio (estudo para o qual importará, a meu ver, compreender as conexões das elites naturais católicas goesas na América sob administração portuguesa). Trata-se porém, de períodos determinantes na vida política deste personagem - desde logo por ser precisamente no Brasil, onde sobreviveu até 1833/1834, no Rio de Janeiro, como professor primário, que publicou uma obra essencial por se vir a tornar, em minha opinião, no catecismo ou vade-mécum do perismo. Falo do Dialogo entre um doutor em philosofia e um portuguez da India na cidade de Lisboa sobre a Constituição Politica do Reino de Portugal, suas vantagens e meios de mantel-a. Dedicado á Mocidade da India pelo seu compatriota Bernardo Peres da Silva, Deputado eleito ás Cortes de Lisboa de 1826, pelos Estados da India (Rio de Janeiro, Tipografia Nacional, 1832). ${ }^{8}$ Aí, sob a capa de uma animada discussão, Peres traça com clareza o travejamento do seu programa político e consequentemente revela a arquitetura do perismo - o qual pode ser, a meu ver, ${ }^{9}$ definido em traços largos como uma forma de organização constitucional que (i) privilegia as elites naturais católicas ao atribuir funções relevantes a conselhos e magistraturas periféricas por elas domináveis, enquanto as promove através da representação parlamentar, em Lisboa; (ii) desvaloriza os poderes centrais e a magistratura letrada de origem reinol; (iii) insiste na divisão de poderes como forma de os repartir por vários centros periféricos; e (iv) assenta num sistema de fontes e ensino do direito fundado numa forte base local, hegemonizado (a) pela prática dos tribunais locais; (b) pelo ascendente dos advogados provisionários (OLIVEIRA, 2016b) e (c) por uma proposta de organização judicial descentralizadora que enfatiza o júri.

Peres conseguiu, creio, e para além do exemplo de tenacidade, oferecer às elites naturais católicas aquilo de que necessitavam para prosseguir na busca

8 São raríssimos os exemplares existentes do Dialogo. Julgo não haver nenhum nas bibliotecas públicas portuguesas e, em Goa, apenas conheço o exemplar fotocopiado conservado no XCHR, e mesmo esse está incompleto. Por assim ser, reproduzi a obra na íntegra como anexo à minha dissertação de doutoramento: OLIVEIRA, 2014, anexo III.

9 Trata-se assim de uma tentativa de teorização da minha autoria, baseada no estudo dos escritos de Peres da Silva e na aplicação efetiva das propostas que aí apresentou por parte dos seus seguidores. 
da satisfação das suas justas ambições: um programa político exequível e socialmente adequado (LOBO, 2016).

$\mathrm{O}$ que concluir no que toca à vida de Peres enquanto parlamentar durante este período? Destaco três aspetos.

Por um lado, apesar de não se ter conseguido fazer escutar nas Cortes entretanto dissolvidas, os processos eleitorais que o guindaram a representante dos povos do Estado da Índia têm uma importância simbólica imensa: 14 de janeiro de 1822 representa a primeira grande vitória política evidente (no sentido de ser por todos visível) das elites naturais católicas após a instauração do liberalismo constitucional em Goa. Já o segundo ato eleitoral corresponde a uma vitória dos peristas sobre aqueles que consideravam ser os seus principais adversários em terras de Goa: a dupla composta pelo vice-rei D. Manuel de Portugal e Castro e pelo desembargador Lousada.

Por outro lado, o facto de Peres se ter visto impossibilitado de intervir desde a cadeira conquistada nas Cortes não significou que a sua voz - e através dela as dos que o elegeram - se tivesse deixado de ouvir. Não só o fez graças ao "protesto" que mandou publicar quando se encontrava já foragido como também através de vários requerimentos recentemente descobertos e estudados (OLIVEIRA, 2014, p. 146-153).

Finalmente, se é certo que a presença de Peres em Lisboa o obrigou a emigrar - primeiro para Inglaterra, depois para o Brasil -, a verdade é que, hoje, refletindo friamente, é possível considerar que todos esses incómodos tenham contribuído para o sucesso da sua carreira política. Caso não tivesse sido forçado ao exílio, Peres provavelmente não teria escrito o Dialogo (uma obra pequena mas fundamental na história político-constitucional goesa, e creio que também portuguesa), não teria contactado de perto com os seus correligionários refugiados em Inglaterra - e é sabido como os tempos de expatriação aproximam os que partilham dos mesmos ideais -, não teria conseguido acompanhar tão atentamente as teorias dominantes na época (nomeadamente as de Bentham, que admirava - OLIVEIRA, 2013) e, certamente, não teria sido escolhido por D. Pedro para prefeito do Estado da Índia em 1834. Caso não passasse de um personagem mais obscuro, retornando a Goa logo após a constatação do encerramento das Cortes, D. Pedro tê-lo-ia contemplado? Não creio.

Tornemos, pois, ao período da prefeitura, época tão importante quanto agitada e dramática. Após a nomeação, Peres depressa se pôs em marcha rumo a 
Pangim e tomou posse a 14 de janeiro de 1835. A história da prefeitura é breve mas decisiva: em termos efetivos, Peres não exerceu o poder em Goa durante mais de uma quinzena de dias (foi deposto por uma revolta militar a 1 de fevereiro do mesmo ano); no entanto, nada voltou a ficar na mesma no Estado da Índia (OLIVEIRA, 2014, p. 114-117). Após algumas semanas de indeterminação, o prefeito e um punhado dos mais influentes peristas abandonam Goa e exilam-se primeiro em Bombaim. Instalam-se depois em Damão, onde Peres continua a desempenhar funções de prefeito (MONIZ, 2000, vol. I, p. 200-205: vol II, p. 178-193). Entretanto, em Goa, o poder é assumido por um governo provisional composto por antiperistas. Consequentemente, ficou "assim a India portuguesa dividida em dois govêrnos entre si independentes, com o escândalo dos visinhos e grande regosijo dos ingleses até à chegada do governador geral, o barão de Sabroso" (SALDANHA, 1990, p. 259). Note-se, porém, que Sabroso chega a Goa apenas em 1837. É com ele que a situação política amaina e que os processos eleitorais se regularizam. O setembrismo determinara a suspensão do funcionamento das Cortes durante algum tempo, pelo que facilmente se compreende que os deputados indianos só reaparecessem em Lisboa no ano de 1838. Peres foi - como era justo e necessário, sublinham os seus apoiantes - eleito sucessivamente em 1838, 1839 e 1842. Isto é, até ter morrido em Lisboa no dia 14 de novembro de 1844 . Ora, o grosso da sua atividade parlamentar efetiva remonta a este período; as muitas intervenções parlamentares que fez representam um reforço doutrinal assaz importante para o perismo e o complemento indispensável do Dialogo escrito no Rio. Mas este não constitui o seu único legado. A herança de Peres também se repercutiu noutros sentidos. Um deles foi ter inaugurado uma longa e constante série de deputados provindos das elites naturais católicas em representação de Goa que procuraram assegurar a defesa dos interesses do seu grupo no parlamento português - o que, naturalmente, contribuiu para o fortalecimento dessa fatia da sociedade goesa.

Como é facilmente compreensível, um dos maiores desafios que o perismo se viu obrigado a enfrentar foi o da morte do seu criador e principal ideólogo: seria capaz de subsistir mesmo sem Bernardo Peres da Silva?

Roberto Bruto da Costa, ele próprio um membro destacado das elites naturais católicas, ponderou sobre a questão: 
Vivendo sob o regimen de pressão a classe nativa, apezar de estarem separados por castas, todos os indigenas se uniam em amplexo fraternal quando se tratava do interesse commum, e d'aqui resultou que, na 1. a eleição de deputados em 14 de janeiro de 1822, fossem eleitos o dr. A. J. Lima Leitão ep., Bernardo Peres da Silva br., e Constancio Roque da Costa br., com votos dos charodós e bramanes, e que na eleição d'um membro da junta provisional em 7 de março do mesmo anno todos os nativos votasse no padre Paulo Antonio Dias da Conceição, da casta sudra; e tudo isto contra o partido dos poderosos.

Esta compactidão continuou até o anno de 1845, sendo muito insignificante o numero dos que se desgarravam por ambição pessoal (BRUTO DA COSTA, 1920, p. 200-201).

Consequentemente, o período balizado por 1844 (relevando, desde logo, as eleições de 1845) e os alvores da década de 1870 (quando se alcança, muito por ação dos deputados pertencentes às elites naturais católicas, a extinção do exército da Índia, derradeiro reduto de vários dos seus principais rivais) vai ser determinante para se aferir não só da vitalidade como também do efetivo sucesso do perismo.

Creio que os esforços em prol da manutenção da herança política de Peres se repercutem em várias frentes, de entre as quais avulta o cordão de parlamentares que se assumiam como continuadores do antigo prefeito. No entanto, e em paralelo, essa ação na arena política parece-me ter sido muito eficazmente complementada - para não dizer mesmo estimulada - por alguns autores, todos eles pertencentes às elites naturais católicas, cujas obras se concatenam e se tornaram essenciais para a compreensão da história literária, política, jurídica e social da Goa oitocentista. Cingir-me-ei hoje a três, que penso desempenharem um papel de maior importância nesta constelação de literatos peristas.

Falo do pioneiro Filipe Nery Xavier, desde logo com a verdadeira apologia das elites naturais católicas que dá a conhecer ao público em 1846, no seu O Gabinete Litterario das Fontainhas, mas também com a edição que, dois anos mais tarde, faz do Huma viagem de duas mil legoas de Cláudio Lagrange Monteiro de Barbuda (que não me parece poder ser reduzida a simples literatura de viagem, lendo nas suas páginas e vendo no contexto da edição um profundo significado político - OLIVEIRA e CALEIRA, 2018). Falo, menos de uma vintena de anos depois, de Luís Manuel Júlio Frederico Gonçalves, com a sua Illustração Goana 
(1864-1866) - na qual vejo também um eficaz elemento de promoção do legado de Peres, desde logo na sequência de biografias de alguns dos principais atores políticos da época, que abre precisamente com a do prefeito. Aliás, de entre os autores que conheço, o primeiro a chamar a atenção quer para a existência do perismo enquanto corrente que virá a transcender a vida e obra do prefeito, quer para a necessidade de encarar Peres numa dupla vertente ("Em Bernardo Peres da Silva, como em todos os espiritos grandes, que passam pelas phazes tumultuosas da governação, houve dois entes distinctos - o pensador e o estadista") foi o ainda muito jovem mentor da Illustração (GONÇALVES, 1864). E falo também de Jacinto Caetano Barreto Miranda. Os seus Quadros historicos de Goa são precisamente contemporâneos da Illustração (coincidência que acredito não poder ser ignorada de um ponto de vista nem literário, nem político) e parecem-me ter constituído, no estado presente da investigação que venho desenvolvendo, um elemento determinante na consolidação do perismo e na promoção das causas mais estremecidas pelas elites naturais católicas - como em breve procurarei ilustrar. As duas obras em questão - tal como, na geração anterior, acontecera com $O$ Gabinete Litterario - conheceram um sucesso sem precedentes entre as elites naturais católicas que constituíam a massa culta de Goa: "Devido à grande personalidade do seu director, Filipe Nery Xavier, erudito autor de uma Nobiliarquia Goana, esta publicação [O Gabinete Litterario] fez escola (DEVI e SEABRA, 1971, p. 142)". E, noutro passo:

Mas logo no ano seguinte começou a publicar-se em Margão uma revista literária que viria a ser de importância capital: a Ilustração Goana. [...] foi talvez a revista literária que maior influência teve na vida cultural do país. Se não foi a primeira revista literária de Goa, foi sem dúvida a mais influente, e mesmo a primeira que perdeu grande parte do carácter de divulgação que até então as revistas assumiam" (DEVI e SEABRA, 1971 p. 143).

E ainda, reportando-me a considerações publicadas por Leopoldo da Gama no Heraldo (edição de 21 de maio de 1909):

Eu tinha então uns 15 ou 16 anos. Cursava em Mapuçá a "Philosophia" pela postila do padre mestre Constantino Barreto quando, sem nenhum desses indícios que precedem de ordinário as novidades de sensação, vem o 10 volume dos "Quadros 
históricos de Goa" explodir como uma bomba no meio de uma geração já aliás acostumada às vigorosas discussões políticas encetadas por Bernardo Francisco da Costa e aos brilhantes "Estrangeiros" de Filipe da Piedade Rebelo em O Ultramar. Foi um acontecimento. O leitor encantado suspendia-se das páginas daquele livro onde palpitava a alma da Pátria. Nada que se parecesse com aquilo saíra à luz. E dizia-se que o autor era um jovem de 21 anos [...]. Os Quadros históricos de Goa exalavam o aroma da mocidade e o fervor da religião do patriotismo, soltando notas vibrantes que vinham acordar ecos nos mais profundos recessos da alma do país. [...]. Seria um impossível descrever hoje a sensação que produziu dentro e fora do País a aparição do I volume dos Quadros históricos.

O livro tomou de assalto o espírito público. Como Byron, o jovem escritor podia exclamar: “Fui uma noite deitar-me 'desconhecido' e era já 'célebre' quando acordei na manhã seguinte".

E de facto o seu nome encontrava as maiores ovações em todos concelhos da Índia Portuguesa.

Os velhos folgavam de ver reproduzidos na tela dos Quadros, com o calor de uma prosa até ali desconhecida no nosso meio, alguns dos mais dramáticos episódios dos dias da sua infância. Os moços, de ver recontadas tão bem as lendas da história pátria, já por eles ouvidas, no conchego do lar, aos pais e avós, nas longas noites de inverno.

Quanto aos rapazes de então, corações virgens, almas susceptíveis de profundas emoções, não teriam vertido lágrimas sobre as páginas que descreviam a morte de Prates e as hecatombes de Gaspar Dias e Tiracol?

Estava-se ainda numa época de ardentes crenças.

Ao I volume dos Quadros históricos seguiram-se outros, actuando poderosamente no movimento literário que se operava então em Goa (apud COSTA, 1997 vol. I p. 105-107 e DEVI e SEABRA, 1971, p. 154-155).

Mais: ambos autores mereceram os favores do então muito influente Tomás Ribeiro, o qual não regateia elogios a Peres - Barreto Miranda é diretamente elogiado nas Jornadas (para além de assinar uma biografia de Ribeiro publicada em Margão em 1871) e Luís Manuel Júlio Frederico Gonçalves tornar-se-á num dos advogados provisionários goeses mais escutados em Lisboa (RIBEIRO, 1874, p. 39; OLIVEIRA, 2015). 
Falo finalmente de Miguel Vicente de Abreu, autor de uma trilogia também ela determinante: a Relação das alterações politicas de Goa desde Setembro de 1821 até 18 de Outubro de 1822; o O governo do vice-rei Conde do Rio Pardo no Estado da India Portugueza. Desde 1816 até 1821 e a Noção de alguns filhos distinctos da India Portugueza que se illustraram fora da patria (dados ao prelo respetivamente em 1862, 1869 e 1874), aos quais se tem de juntar a, mais antiga, versão acrescentada e comentada do Bosquejo histórico de Goa de Cottineau de Kloguen.

Anos mais tarde, em 1888, no seu Goa antiga e moderna, o descendente Frederico Diniz d'Ayalla já se refere ao perismo como um conceito consolidado e absolutamente operacional. E nessa obra - o que tão pouco me parece poder ser lido como um acaso - dedica palavras de grande azedume a Nery Xavier, Barreto Miranda e Vicente de Abreu. Todos arautos da causa do prefeito, que o autor tanto vitupera (AYALLA, 2011, p. 29-30). Essa é, a meu ver, uma robusta demonstração a contrario sensu do sucesso da ação daqueles escritores na promoção dos ideais de Peres.

\section{Uma ilustração: tentativa de demonstração de um direito pré-existente nos Quadros Historicos de Barreto Miranda}

Jacinto Caetano Barreto Miranda foi, assim, um dos mais importantes historiadores e pensadores sobre o perismo em meados do século XIX. Já me reportei ao estudo que dedicou às Eleições e deputados, entre 1822 e 1842, um trabalho extremamente denso que - também por o autor pertencer ao universo das elites naturais católicas e ter tido possibilidade de contatar com muitos dos que tinham vivido os tempos atribulados da instauração do liberalismo constitucional e, consequentemente, dos alvores do perismo - ainda hoje se destaca na produção existente sobre o tema. ${ }^{10}$ Tal singularidade obriga a que esse ensaio seja merecedor de um estudo aturado.

10 Para além dos já citados Aleixo Costa, Leopoldo da Gama, Vimala Devi e Manuel de Seabra, e Diniz d'Ayalla, são-lhe reservadas palavras amáveis no Diccionario de Inocêncio, frisando-se a boa aceitação dos Quadros: "É curiosa esta obra pelas noticias que encerra. Foi publicada em fascículos [...]. Recebeu o auctor muitos elogios por este trabalho, não só da imprensa indiana, mas do continente do reino" (SILVA e ARANHA, 1883, p. 104). Note-se que todos estes depoimentos 
Contudo, de momento, pretendo apenas debruçar-me sobre as páginas iniciais do dito ensaio. É aí que o autor aborda dois aspetos que me parecem ser particularmente interessantes. Por um lado, (i) a necessidade de ser assegurada liberdade eleitoral plena ao Estado da Índia (ou seja, e em termos práticos, às suas elites católicas). Por outro, e a corroborar o primeiro ponto, (ii) uma original tentativa de demonstração da antiguidade do direito de sufrágio dos goeses (mais uma vez, das suas elites católicas), o qual, segundo a convicção do autor, era muitíssimo anterior às conquistas oitocentistas do liberalismo constitucional - que, portanto, não o criara, mas apenas robustecera.

Considerarei brevemente cada uma destas coordenadas.

No que diz respeito ao desaconselhamento de intervenções externas (sobretudo governamentais) no exercício do direito de voto pelos goeses, Barreto Miranda funda-se em dois argumentos. Em primeiro lugar, defende que o Estado da Índia se achava num estádio de "illustração" e "civilização" (expressões empregadas pelo autor) que tornava desnecessárias e desadequadas quaisquer ingerências daquele género. Apesar de Barreto Miranda não o afirmar claramente, paira a sensação de que pretende sublinhar as grandes diferenças que nessa matéria existiam entre os territórios dependentes de Goa e as possessões africanas (MIRANDA, 1865, p. 75). Em segundo lugar, sustenta que tal ingerência, para além de despropositada, era "perniciosissima entre os povos da India, onde a pressão do governo se combina com a indole pacifica dos eleitores avezada por seculos por um regime puramente militar, para que o menor aceno dos poderes se converta em uma ordem, que religiosamente deve ser cumprida" (MIRANDA, 1865, p. 75). Essa tendência teria sido quebrada durante a vida de Bernardo Peres da Silva, sucessivamente eleito para as cadeiras das Cortes, mas compreende-se que, morto o estadista, os seus seguidores temessem a instalação de um sentimento generalizado de subserviente apatia e indiferença relativamente aos deputados enviados pela Índia e para representar a Índia. Tratava-se, afinal, de garantir um dos pilares fundamentais do perismo e da estratégia de consagração das elites naturais católicas das Velhas Conquistas.

Volto agora os olhos para o segundo dos aspetos suprarreferidos: a defesa da tese da antiguidade do direito de voto em Goa - e, mais concretamente, 
do direito de voto dos goeses. Barreto Miranda explana o seu ponto de vista envolvendo-o em algum dramatismo, como era apreciado na época:

O direito do suffragio dos povos de Goa he antigo, e data do seculo da sua conquista. Antes que fossemos constitucionaes, eramos eleitores; antes que fossemos soberanos nos foros civicos, eramos soberanos nas escolhas dos mandatarios (MIRANDA, 1865, p. 77).

Como justifica tais asserções? Onde vai o autor encontrar os vestígios desse quase proto-direito eleitoral, que asseverava serem tão remotos? À capacidade de eleger os vereadores dos senados das câmaras das Velhas Conquistas - primeiro, e durante séculos, apenas o das Ilhas de Goa; mais tarde, depois de Pombal, também os de Bardez e Salsete.

Mais do que discutir a admissibilidade de tal precedente, interessa-me sobretudo ter presente o esforço que representa esta original genealogia eleitoral. Barreto Miranda adota uma postura relativamente realista e apressa-se a admitir que tal direito, embora na sua opinião existisse não fora, porém, efetivamente exercitado. Isto porque "Inutil he dizer que essas eleições não foram á contento dos povos, e filhas da liberdade, como garantiam os privilégios". Consequentemente, "[a]s funcções populares forçosamente haviam de ser uma decepção" (MIRANDA, 1865, p. 77-78).

Quais eram as causas dessa "decepção", que tolhia um direito que Barreto Miranda advogava ser de longa data? O autor enumera quatro, a maioria de natureza política.

Em primeiro lugar, invoca "o absolutismo do seculo". Depois, "o despotismo do vice-rei, nada menos que um nababo na sua omnipotencia" (MIRANDA, 1865, p. 78). Em seguida, lembra a política de descentralização (que entende no sentido de delegação tendencial de poderes e ratificação tácita dos procedimentos dos vice-reis) adotada por Lisboa em virtude da grande distância que a separava de Goa. Tal opção, no entanto, servira para fortalecer o "governo dos tyrannos militares da India". Muito disto, note-se, faz eco de algumas passagens do Dialogo de Peres da Silva. A nota original de Barreto Miranda parece-me, assim, ser a convicção de que o liberalismo constitucional, em matéria de direito de sufrágio, pouco criara ex novo, antes confirmara, ratificara e ampliara direitos há muito consagrados. Penso ser possível admitir que o autor, ao defender 
esta tese, estaria acima de tudo empenhado em demonstrar a indestrutibilidade dessas veneráveis prerrogativas por parte de quem as quisesse pôr em causa: os goeses não só se achariam num patamar "civilizacional" mais avançado como exercitavam direitos que, mesmo que entendidos de forma diferente à luz do ideário liberal constitucional, tinham raízes muito antigas.

Em quarto e último lugar, alude aos "costumes doceis" e às "tendencias pacificas" dos goeses, pouco propensos a uma "sublevação em nome dos direitos da humanidade" em virtude de terem sido cruelmente dominados durante centúrias: aos excessos da dominação muçulmana tinham sucedido os dos vice-reis nomeados por Portugal (MIRANDA, 1865, p. 78-79).

Aqui chegado, como prossegue Barreto Miranda? Envereda por uma leitura da história política de Goa que me parece original. Uma vez que o que estava em causa não era tanto a conquista de um direito (o qual teoricamente já existiria) mas a tentativa de o exercitar (ou mesmo a sua recuperação), lia os acontecimentos dos séculos anteriores a essa luz. "O terror foi o motor da eleição dos cargos da cidade" (MIRANDA, 1865, p. 79), afirma a dado passo, e a ele recorriam as principais autoridades reinóis, confiadas na distância da Lisboa e na dificuldade de reação dos goeses espoliados das suas regalias. O resultado estaria à vista de todos:

As eleições assim falseadas eram um paladio fementido dos povos, que não podia explicar a soberania do elemento popular. A melhor regalia desses tempos sacrificada no altar levantado pelo servilismo ao governo, e entregue nas mãos da oligarchia habituada a viver no poder, passou depois de muitos annos com os indígenas, que pareciam estar desherdados dos seus foros, mas a influencia dos vice-reis por demais potente para soffrer resistência, nunca chamou á governança do município vereadores que não fossem da sua facção (MIRANDA, 1865 p. 80).

Mesmo as esparsas tentativas no sentido de reverter a situação - quer fossem locais, quer vindas do reino (o autor concede particular atenção ao episódio da conjuração dos Pintos e às reformas pombalinas; mais tarde aludirá à bardezada) - eram rapidamente esmagadas pela classe dominante e pela "educação filha do egoismo das castas". Só lentamente, muito lentamente, as elites naturais católicas - "uma pequena parte do povo penetrada das suas regalias" que "ousou sair do statu quo, em que se achava a sociedade indiana"(MIRANDA, 
1865 , p. 81) foram conquistando lugar no senado das Ilhas, isto é, puderam timidamente exercitar os seus direitos. E aqui relembro que Bernardo Peres da Silva começou efetivamente a sua carreira política como vereador daquela câmara.

É nesta conjuntura pouco risonha que irrompe a Constituição, assumindo, na argumentação de Barreto Miranda, com formidável ímpeto um papel de garante do reconhecimento de direitos e prerrogativas já existentes, mas jamais colocados em prática devido aos escolhos que reiteradamente se lhes opunham:

[A constituição] não só abateu o mundo do despotismo e da superstição, mas ainda esbroou o colosso das distincções das côres e das classes, sobre cujas ruinas ergueu-se jucunda a homerica figura do marquez de Pombal, quando a paschoa da ressurreição politica fez abraçar no campo legal classes, que por três seculos se repelliam escandalosamente, e que o marquez se esforçára por unir. A constituição, pois, que foi feliz para todos os povos, foi felicissima aos povos da India, onde além de evitar choques tristissimos dos dois elementos diversos, encontrou uma sociedade, que o progresso preparára para a liberdade (MIRANDA, 1865 p. 82).

No entanto - e este é o argumento derradeiro da tese de Barreto Miranda -, o governo não acompanhou esta "transformação social" que permitia que "o paiz libertado do statu quo" fosse "nas azas da liberdade seguindo o caminho progresso impelido pela fé no futuro". Na verdade, "Coisa notável! O governo não o guiou, nem se deixou guiar atraz delle, e ao tempo que devia dar o impulsou, recuou. A lucta entre ambos foi declarada. $O$ governo foi retrogrado; o povo foi progressivo" (MIRANDA, 1865, p. 82).

Ora, e qual seria a melhor arena para ambas as fações doravante de defrontarem? Barreto Miranda não hesita na resposta:

Justando ambos, as suas pugnas se revelam melhor nas eleições de deputados, e a presente narrativa mostrará no campo eleitoral d'um lado o povo esforçando-se por ser livre e desassombrado diante da urna, e procurando dignos representantes; e d'outro o governo com o cortejo dos seus beleguins trabalhando por converter em uma decepção os direitos [...], semeando á mão larga corrupção e vergonha para segurar para si bandos de eleitores subservientes, gloriando-se do triumpho da candidatura dos seus amigos. (MIRANDA, 1865, p. 82-83) 
Não me preocuparei, agora, em comprovar a bondade desta tese - o que pressupõe desde logo um estudo aturado do pacote legislativo pombalino e do funcionamento dos senados das câmaras das Velhas Conquistas, sobretudo os de Bardez e Salsete, muito menos conhecidos do que o das Ilhas de Goa. Há, porém, que chamar a atenção não só para a originalidade que encerra, mas também para o esforço (por ela forçosamente refletido) dos peristas em procurar manter e densificar as principais linhas de força do seu credo (uma das quais era, como vimos, a representação parlamentar) muito após a morte do prefeito, dando assim mostra da vitalidade do movimento.

Partindo do pressuposto de que seria extremamente redutor tomar o perismo como uma mera erupção episódica, temporal e geograficamente limitada, creio ser possível sustentar que o legado do prefeito se manteve quer a partir dos seus próprios escritos quer dos de uma plêiade de homens de letras. Estes souberam não só conservar mas mesmo conformar a proposta do Dialogo e dos discursos parlamentares ao evoluir dos tempos, o que julgo demonstrar de modo feliz como a causa das elites naturais católicas se articula entre política, direito, literatura e perismo - quatro pilares essenciais para se compreender a Goa oitocentista.

\section{Referências}

ABREU, Miguel Vicente de. Noção de alguns filhos distinctos da India Portugueza que se illustraram fora da patria. Nova Goa: Imprensa Nacional, 1874.

ABREU, Miguel Vicente de. Relação das alterações politicas de Goa desde Setembro de 1821 até 18 de Outubro de 1822. Nova Goa: Imprensa Nacional, 1862.

AYALLA, Frederico Diniz d'. Goa Antiga e Moderna. Lisboa: Ésquilo [orig. 1888], 2011.

BRUTO DA COSTA, Roberto. Para a história política da Índia Portuguesa. A hidra do "nativismo", Rebatendo a calúnia de "independência de Goa", "dominio inglês", "ódio aos brancos" e "aniquilamento da colónia portuguesa". Nova-Goa: Tipografia Bragança \& C.a, 1920.

COSTA Aleixo Manuel da. Dicionário de Literatura Goesa. Macau: Instituto Cultural de Macau/Fundação Oriente, 1997.

DEVI, Vimala e SEABRA, Manuel de. A literatura indo-portuguesa. Lisboa: Junta de Investigações do Ultramar, 1971. 
GONÇALVES, Luís Manuel Júlio Frederico. "Bernardo Peres da Silva". Illustração Goana. Periodico Litterario. Primeiro Anno / Nova Goa: Imprensa Nacional, p. 18-19, 1864. COSTA, Joaquim Bernardino Catão da. Genealogia da Familia Costa de Margão, Remontada ao anno anterior a 1580 e apontamentos biográficos d'alguns dos seus membros. Margão: Tipografia do "Ultramar", 1873.

LOBO, Sandra Ataíde. "O sujeito, o cidadão e o colonizado na Goa dos séculos XIX e XX". In XAVIER, A. B. e SILVA, C. N. (org.), O governo dos outros: poder e diferença no império português. Lisboa: ICS-Imprensa de Ciências Sociais, 2016, p. 305-313.

LOBO, Sandra Maria Calvinho Ataíde. O desassossego goês. Cultura e política em Goa do liberalismo ao Acto Colonial. Dissertação (Doutoramento em História e Teoria das Ideias)- Universidade Nova de Lisboa. Lisboa, 2013.

LOPES, Maria de Jesus dos Mártires; MATOS, Paulo Lopes. “Naturais, reinóis e luso-descendentes: a socialização conseguida". In SERRÃO, J. e MARQUES, J. H. O. (ed.), Nova História da Expansão Portuguesa. O Império Oriental (1660-1820), tomo I. Lisboa: Editorial Estampa, 2006, pp. 15-70.

LOPES, Maria de Jesus dos Mártires. Goa Setecentista: Tradição e Modernidade (17501800). Lisboa: Centro de Estudos dos Povos e Culturas de Expressão Portuguesa, Universidade Católica Portuguesa, 1999.

MIRANDA, Jacinto Caetano Barreto. "Quadro XVII. O jornalismo". Quadros Historicos de Goa: tentativa historica. Caderneta II / Margão: Tipografia de "O Ultramar", 1864b, p. 103-115.

MIRANDA, Jacinto Caetano Barreto. "Quadro XVIII. Os martyres da politica”. Quadros Historicos de Goa: tentativa historica. Caderneta II /Margão: Tipografia de O Ultramar, 1864a , p. 115-129.

MIRANDA, Jacinto Caetano Barreto. "Quadro XXV. As Eleições e os Deputados”, 18221842. Quadros Historicos de Goa: tentativa historica. Caderneta III / Margão: Tipografia de 0 Ultramar, p. 74-171, 1865.

MONIZ, António Francisco. Notícias e documentos para a história de Damão - antiga Província do Norte. Lisboa: Associação Fraternidade Damão-Diu e Simpatizantes [orig. 1923], 2000.

OLIVEIRA, Luís Pedroso de Lima Cabral de. "Emancipate your Colonies! Reacções de Bernardo Peres da Silva ao anticolonialismo de Bentham". Estudos Dedicados ao Professor Doutor Nuno Espinosa Gomes da Silva / Lisboa: Universidade Católica Editora, 2013, p. 497-531.

OLIVEIRA, Luís Pedroso de Lima Cabral de. A consagração dos naturais: direito(s) e elites naturais católicas em Goa (1780-1880). Dissertação (Doutoramento em Direito) - Universidade Nova de Lisboa. Lisboa, 2014. 
OLIVEIRA, Luís Pedroso de Lima Cabral de. "Quem sabe o que é um advogado? - A resposta de Luís Manuel Júlio Frederico Gonçalves às tentativas de reforma dos provisionários goeses em 1869". Jahrbuch für Geschichte Lateinamerikas, n. 52, 2015, p. 207-229. OLIVEIRA, Luís Pedroso de Lima Cabral de. "Elites coloniais (Goa)". E-dicionário da terra e do território no império português. 2016a Disponível em https://edittip.net/2016/03/21/ elites-coloniais-goa/. Acesso: 8 de setembro de 2019.

OLIVEIRA, Luís Pedroso de Lima Cabral de. "Magistrados letrados ou provisionários? 0 caso de André Francisco de Bragança (Goa, 1832-1836)". Revista de Teoria e História do Direito, 1/1, 95-108, 2016b. Disponível em https://www.thdulisboa.com/revista-thd. Acesso: 8 de setembro de 2019.

OLIVEIRA, Luís Pedroso de Lima Cabral de; CALEIRA, João Pedro. “Direito, política e sociedade: as Novas Conquistas de Goa durante o Perismo. Os contributos de Nery Xavier e Cláudio Lagrange". In VARELA, L.B. e SASTRE, M.J.S. (coord.), Estudios Luso-Hispanos de Historia del Derecho/Estudos Luso-Hispanos de História do Direito, I. Madrid: Editorial Dykinson, 2018.

OLIVEIRA, Luís Pedroso de Lima Cabral de; COSTA, Pedro do Carmo. "Na Dobragem do Meio Milénio: Elites e Genealogia na 'Oriental Lisboa'”. Raízes \& Memórias / Lisboa, n. 27, p. 55-112, 2010.

PEREIRA, António Simeão e MENEZES Luís Caetano de (atrib.). Refutação analytica do manifesto do governo intruso de Goa, intitulado Governo Provisional do Estado da India Portugueza em nome de S. M. Fidelissima a Rainha, Snra. D. Maria II de 21 de Julho de 1835, Contendo um exame circunstanciado, e esmiuçada confutaçam de todos os fundamentos e razoens, em que os Manifestantes pretendem apoiar a criminoza Rebelliam, $e$ os subsequentes horriveis attentados por elles perpetrados em Goa: Seguida de documentos justificativos, e peças officiaes, extrahidos da Secretaria da Prefeitura, e d'outras repartiçoens publicas, \&c, por um Emigrado de Goa. Bombaim: Oficina Tipográfica de D. Gonçalves, 1835.

RIBEIRO, Tomás, Jornadas. Segunda parte: entre palmeiras (De Pangim a Salsete e Pondá). Coimbra: Livraria Central de Diogo Pires, 1874.

SALDANHA, M. J. Gabriel de. História de Goa (política e arqueológica), vol. I. New Delhi/ Chennai: Asian Educational Services [reed. da 2a ed.1926], 1990.

SILVA, Inocêncio Francisco da Silva e ARANHA, Brito. Diccionario Bibliographico Portuguez. Tomo decimo (Terceiro do supplemento). Lisboa: Imprensa Nacional, 1883.

THOMAZ, Luís Filipe. De Ceuta a Timor. Lisboa: Difel, 1998.

XAVIER, Filipe Nery. "Estado da India. Noção historica de Goa". O Gabinete Litterario das Fontainhas / Imprensa Nacional, Nova Goa, 1ํvolume, 1846. 